\title{
Restoring lower limb blood flow improves conduction velocity in diabetic patients
}

\author{
M.J. Young ${ }^{1}$, A. Veves ${ }^{1}$, J.V. Smith ${ }^{2}$, M. G. Walker ${ }^{2}$, A.J.M. Boulton ${ }^{1}$ \\ ${ }^{1}$ University Department of Medicine, Manchester Royal Infirmary, Manchester, UK \\ ${ }^{2}$ Department of Vascular Surgery, Manchester Royal Infirmary, Manchester, UK
}

\begin{abstract}
Summary Human diabetic peripheral neuropathy is believed to have, at least in part, a microvascular basis. This study was designed to examine the effects of restoration of arterial blood supply on peripheral nerve function in six non-insulin-dependent diabetic patients with peripheral occlusive vascular disease. In the revascularised legs, transcutaneous oxygen increased from a median 37.5 (28.5-45.7 interquartile range) $\mathrm{mmHg}$ to $55.5(53.5-62.5) \mathrm{mmHg}, p=0.036$, mean increase 20.2 (14.8-25.6, $95 \%$ confidence intervals(CI)) $\mathrm{mmHg}$. This was accompanied by a significant improvement in peroneal motor nerve conduction velocity from $31.7(26.5-36.3) \mathrm{m} / \mathrm{s}$ to 33.5 (32.9-
\end{abstract}

$39.4) \mathrm{m} / \mathrm{s}, p=0.04$, mean increase $4.7(1.7-7.7,95 \%$ CI) $\mathrm{m} / \mathrm{s}$. There was no significant change in transcutaneous oxygen or peroneal nerve motor conduction velocity in the contralateral control limbs. This improvement in conduction velocity with improved tissue oxygenation suggests that studies of agents which might indirectly bring about improvements in microvascular blood flow should be urgently considered. [Diabetologia (1995) 38: 1051-1054]

Key words Peripheral neuropathy, peripheral vascular disease.
Evidence that microvascular disease is implicated in the pathogenesis of diabetic peripheral neuropathy can be drawn from histopathological and physiological studies in animals and humans [1]. Observations of the effects of proximal arterio-venous shunts on nerve function in the distal limb have suggested that a reduction in macrovascular blood flow can result in peripheral nerve dysfunction in non-diabetic subjects [2-4]. A recent study demonstrated that peripheral nerve function was inversely correlated to transcutaneous oxygenation in diabetic patients [5]. This is in keeping with experimental work which shows reduced endoneurial oxygenation [6], impaired nerve blood flow and increased arterio-venous shunting

Received: 9 January 1995 and in revised form: 15 March 1995

Corresponding author: Prof. A.J.M. Boulton, University Department of Medicine, Manchester Royal Infirmary, Oxford Road, Manchester M13 9WL, UK

Abbreviations: NIDDM, Non-insulin-dependent diabetes mellitus; $\mathrm{MCV}$, motor conduction velocity; $\mathrm{TcPO}_{2}$, transcutaneous oxygen.
[7], and laser Doppler flux in the nerves of animals and humans [8], and the clinical observation of reduced nerve function in diabetic patients with peripheral vascular disease $[9,10]$. The previous study also examined the effect of revascularisation on nerve function in non-diabetic patients and demonstrated a significant improvement in nerve function with restoration of limb blood flow [5]. The current study was designed to examine the effects of arterial reconstructive surgery on peripheral nerve function in diabetic patients and to act as a possible model for future therapeutic modalities.

\section{Subjects and methods}

All subjects gave informed consent prior to participation in the study, which was performed with the approval of the ethical committee of the Central Manchester Hospitals National Health Service Trust.

Six consecutive NIDDM (non-insulin-dependent) diabetic patients, three male and three female, with symptomatic angiographically-proven femoral artery thromboses suitable for uni- 


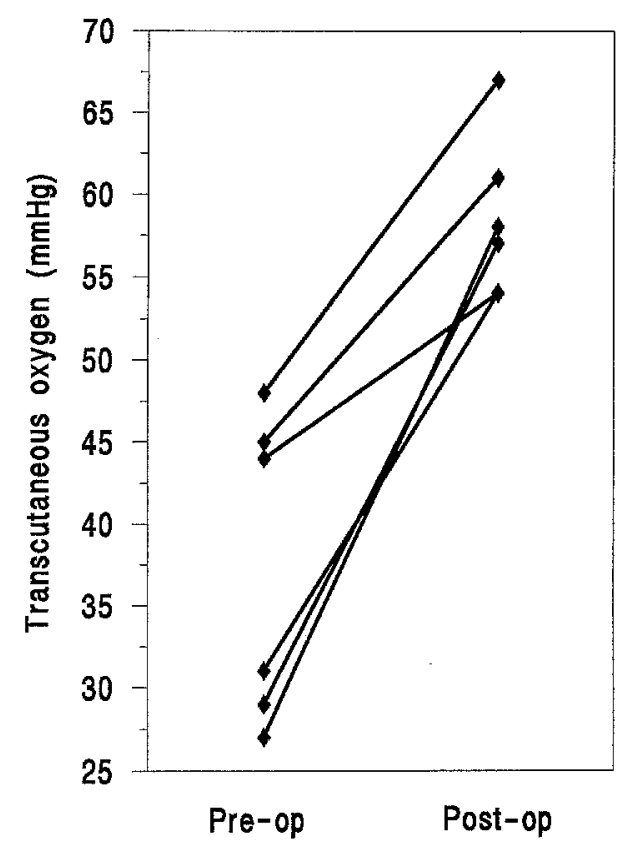

Fig. 1. The change in transcutaneous oxygen tension in the revascularised leg of each subject pre- and post-arterial reconstructive surgery (median 37.5 (28.5-45.7 interquartile range) $\mathrm{mmHg}$ to $55.5(53.5-62.5) \mathrm{mmHg}, p=0.036)$

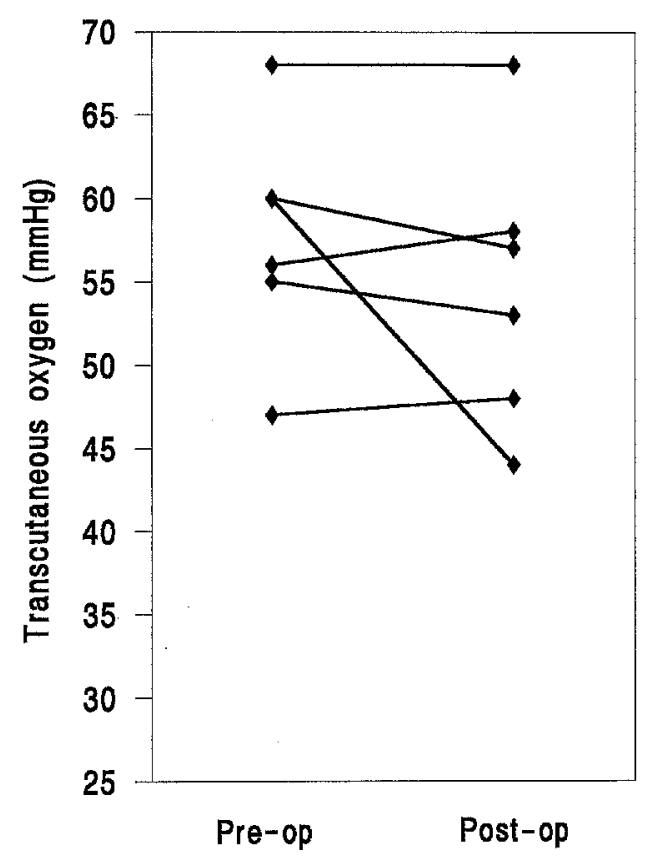

Fig. 2. The change in transcutaneous oxygen tension in the control leg of each subject pre- and post-arterial reconstructive surgery (median 58.0 (49.2-66.0 interquartile range) $\mathrm{mmHg}$ to $53.0(45.0-65.5) \mathrm{mmHg}, p=1.0)$

lateral bypass surgery were included in the study. The operations were not performed for reasons of limb salvage or critical ischaemia. Their median age was $64(58-72)$ years (interquartile range), and duration of diabetes was 7 (3-14) years. All were smokers and none changed their smoking habit during the study. No patient was taking vasoactive drugs. All were treated with aspirin.

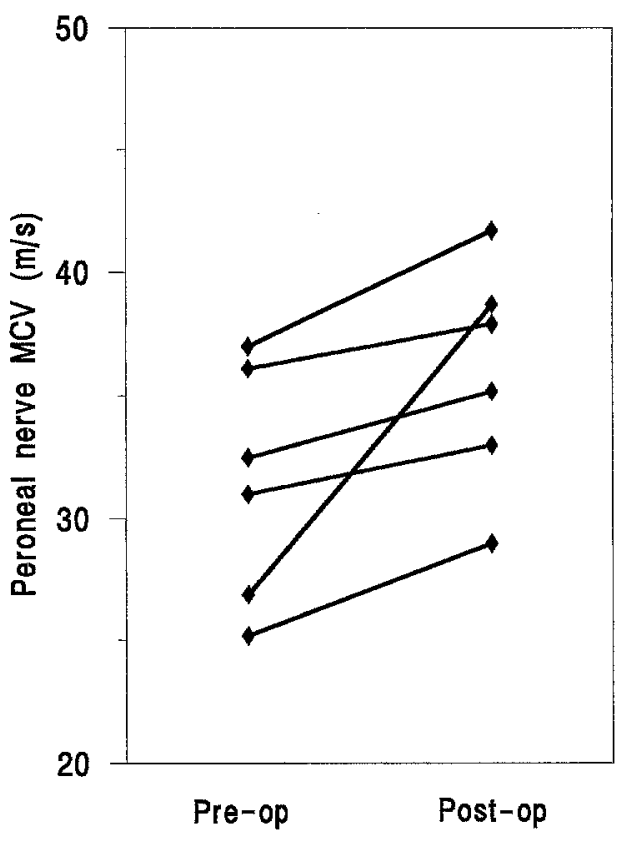

Fig. 3. Changes in peroneal nerve MCV in the revascularised leg of each subject pre- and post-arterial reconstructive surgery (median 31.7 (26.5-36.3 interquartile range) $\mathrm{m} / \mathrm{s}$ to 33.5 $(32.9-39.4) \mathrm{m} / \mathrm{s}, p=0.04)$

Peroneal nerve motor conduction velocity (MCV) and transcutaneous oxygen tension were measured in both lower limbs on the day before, and 6-8 weeks after, bypass surgery. The limb which did not undergo surgery was used as a control for possible changes in the physiological milieu pre- and postoperatively. Blood glucose level was measured in all patients at the time of peroneal nerve MCV to ensure that they were not hypoglycaemic. Peroneal nerve MCV was used as this correlates well with sural sensory nerve conduction velocity, and sural nerve latency is often absent in patients with reduced peroneal MCV [11].

The methods used have been described in detail in a previous paper [5]. Peroneal nerve MCV was measured after equilibration with the patient lying semi-supine in a warm room $\left(>25^{\circ} \mathrm{C}\right)$, using standard surface electrodes and a Medelec MS92a neurophysiology system (Medelec, Old Woking, Surrey, UK). Printouts were made of the latencies and these were then measured independently, without knowledge of the patient's identity, or indication of which limb had been measured. Transcutaneous oxygen $\left(\mathrm{TcPO}_{2}\right)$ was measured at the site of the extensor digitorum brevis using a TINA TCM3 Oxygen monitor (Radiometer, Copenhagen, Denmark) with an electrode temperature of $44^{\circ} \mathrm{C}$. The recorded $\mathrm{TcPO}_{2}$ was the stable oxygen level after the monitor was attached for at least $20 \mathrm{~min}$ to the patient.

\section{Statistical analysis}

All results were analysed using Minitab statistical software (Minitab Inc., State College, Pa., USA) and all comparisons were performed as paired Wilcoxon rank sum tests. 


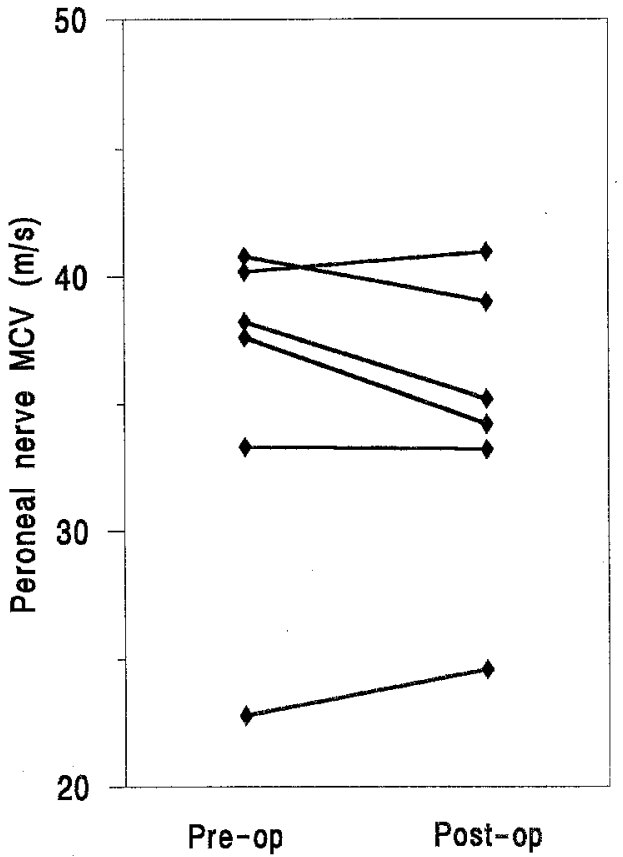

Fig. 4. Changes in peroneal nerve MCV in the control leg of each subject pre- and post-arterial reconstructive surgery (median 35.5 (25.5-39.5 interquartile range) $\mathrm{m} / \mathrm{s}$ to 34.2 (26.740.3) $\mathrm{m} / \mathrm{s}, p=0.83$ )

\section{Results}

The results are displayed graphically in Figures 1-4.

In the revascularised legs, transcutaneous oxygen increased from a median 37.5 (28.5-45.7 interquartile range) $\mathrm{mmHg}$ to $55.5(53.5-62.5) \mathrm{mmHg}$, $p=0.036$, mean increase $20.2(14.8-25.695 \%$ confidence intervals) $\mathrm{mmHg}$. This was accompanied by a significant improvement in peroneal motor nerve conduction velocity from median $31.7(26.5-36.3) \mathrm{m} /$ $\mathrm{s}$ to $33.5(32.9-39.4) \mathrm{m} / \mathrm{s}, p=0.04$, mean increase 4.7 $(1.7-7.7,95 \%$ confidence intervals $) \mathrm{m} / \mathrm{s}$.

There was no significant change in transcutaneous oxygen or peroneal nerve motor conduction velocity in the contralateral control limb; median $\mathrm{TcPO}_{2}$ presurgery $58.0(49.2-66.0) \mathrm{mmHg}$, post-surgery 53.0 (45.0-65.5) $\mathrm{mmHg}$; median peroneal motor nerve conduction velocity, pre-surgery $35.5(25.5-39.5) \mathrm{m} / \mathrm{s}$, post-surgery34.2 $(26.7-40.3) \mathrm{m} / \mathrm{s}, p=0.83$ and $p=1.0$ respectively.

\section{Discussion}

This study demonstrates that improving tissue oxygenation can improve nerve conduction velocity in diabetic patients. It extends the findings of our previous study which demonstrated improvement in nondiabetic patients [5]. The mean increase in peroneal MCV of around $15 \%$ is greater than that reported in trials with gamma-linolenic acid (Scotia Pharmaceu- ticals, Guildford, Surrey, UK), an open labelled study of the use of lisinopril (Zeneca pharmaceuticals, Macclesfield, UK), both of which have, in part, been thought to contribute to improved microvascular blood flow $[12,13]$, or in trials of the aldose reductase inhibitor Tolrestat (Wyeth Laboratories, Taplow, Berks., UK) [14], which is now a prescribable therapy for peripheral neuropathy in many countries around the world. Although such improvements have not been demonstrated in double-blind controlled studies in man, vasodilator and other therapies believed to improve peripheral blood flow have been successful in preventing peripheral neuropathy in experimental diabetes [15]. Improvements in microvascular haemodynamics have been described in patients following vascular reconstructive surgery in association with increases in $\mathrm{TcPO}_{2}$ of the same magnitude to those seen in this study [16]. In view of these results [16], and the results of the past [5], and present studies, which show improvement in nerve conduction follow up a direct improvement in tissue oxygenation, studies of agents which might indirectly bring about improvements in microvascular blood flow should be urgently considered.

\section{References}

1. Watkins PJ (1992) Clinical observations and experiments in diabetic neuropathy. Diabetologia 35: 2-11

2. Sladky JT, Tschoepe RL, Greenberg JH, Brown MJ (1991) Peripheral neuropathy after chronic endoneurial ischaemia. Ann Neurol 29: 272-278

3. Wilbourn AJ, Furlan AJ, Hulley W, Ruschhuap TW (1983) Ischaemic monomelic neuropathy. Neurology 33: 447-451

4. Riggs JE, Moss AH, Labosky DA, Liput JH, Morgan JJ, Gut Mann L (1989) Upper extremity ischaemic monomelic neuropathy: a complication of vascular access procedures in uremic diabetic patients. Neurology 39: 997-998

5. Young MJ, Veves A, Walker MG, Boulton AJM (1992) Correlations between nerve function and tissue oxygenation in diabetic patients: further clues to the aetiology of diabetic neuropathy? Diabetologia 35: 1146-1150

6. Stevens EJ, Lockett MJ, Carrington AI, Tomlinson DR (1993) Essential fatty acid treatment prevents nerve ischaemia and associated conduction anomalies in rats with experimental diabetes. Diabetologia 36: 397-401

7. Tesfaye S, Harris N, Jakubowski JJ et al. (1993) Impaired nerve blood flow and arterio-venous shunting in human neuropathy: a novel technique of nerve photography and flourescein angiography. Diabetologia 36: 1266-1274

8. Newrick PG, Wilson AJ, Jakubowski J, Boulton AJM, Ward JD (1986) Sural nerve oxygen tension in diabetes. BMJ 293: 1053-1054

9. Maser RE, Steenkiste A R, Dorman JS et al. (1989) Epidemiological correlates of diabetic neuropathy: report from Pittsburgh epidemiology of diabetes complications study. Diabetes 38: 1456-1461

10. Ram Z, Sadeh M, Walden R, Adar R (1991) Vascular insufficiency quantitatively aggravates diabetic neuropathy. Arch Neurol 48: 1239-1242

11. Veves A, Malik RA, Lye RH et al. (1991) The relationship between sural nerve morphometric findings and measures 
of peripheral nerve function in mild diabetic neuropathy. Diabet Med 8: 917-921

12. Keen $\mathbf{H}$ and The gamma-linoleic acid multicentre trial group (1993) Treatment of diabetic neuropathy with gamma-linoleic acid. Diabetes Care 16: 8-15

13. Reja A, Tesfaye S, Harris N, Ward JD (1993) Improvement in nerve conduction and quantitative sensory tests following treatment with lisinopril. Diabet Med 10:S18

14. Boulton AJM, Levin S, Comstock J (1990) A multicentre trial of the aldose reductase inhibitor, tolrestat, in patients with symptomatic diabetic neuropathy. Diabetologia 33: 431-437
15. Cameron NE, Cotter MA (1993) Potential therapeutic approaches to the treatment or prevention of diabetic peripheral neuropathy. Evidence from experimental studies. Diabet Med 10: 593-605

16. Jacobs HJHM, Beckers RCY, Jorning PJG, Slaaf DW, Reneman RS (1990) Microcirculatory haemodynamics before and after vascular surgery in severe limb ischaemia the relation to post-operative oedema formation. Eur J Vasc Surg 4: 525-529 